\section{Early infliximab antibody test- ing does not prevent infusion reactions when reinitiating infliximab}

\author{
Joseph D. Feuerstein \\ Department of Medicine and Division of \\ Gastroenterology, Beth Israel Deaconess \\ Medical Center, Harvard Medical School, \\ Boston, MA, USA
}

\begin{abstract}
Infliximab drug level checking has started to revolutionize the treatment of inflammatory bowel disease, allowing for more accurate dosing. Recently, Brandse and colleagues and Gagniere and colleagues both noted the potential benefit of a re-introduction of infliximab after prior failure in patients with Crohn's disease. Unfortunately though, approximately $1 / 3$ of patients stopped the drug due to side effects of the attempted retreatment from infusion reactions. In their study, they also noted that concomitant usage of a thiopurine did not provide any additional benefit. Presumably, majority of these reactions are secondary to antibody formation to infliximab. In order to reduce the risk of infusion reactions, we present a case of a patient with Crohn's disease who was retried on infliximab and had antibody testing after the first dose to assess if it would be safe to continue the drug, as most infusion reactions occur at the second dose.
\end{abstract}

\section{Introduction}

Infliximab drug level checking has started to revolutionize the treatment of inflammatory bowel disease, allowing for more accurate dosing. ${ }^{1,2}$ Recently, Brandse and colleagues and Gagniere and colleagues both noted the potential benefit of a re-introduction of infliximab after prior failure in patients with Crohn's disease. ${ }^{3,4}$ Unfortunately though, approximately $1 / 3$ of patients stopped the drug due to side effects of the attempted retreatment from infusion reactions. In their study, they also noted that concomitant usage of a thiopurine did not provide any additional benefit. Presumably, majority of these reactions are secondary to antibody formation to infliximab. In order to reduce the risk of infusion reactions, we present a case of a patient with Crohn's disease who was retried on infliximab and had antibody testing after the first dose to assess if it would be safe to continue the drug, as most infusion reactions occur at the second dose.

\section{Case Report}

A 44-year-old female with a history of Crohn's ileocolitis with multiple complex perianal fistulas was diagnosed in 1998. She was initially treated with mesalamine and prednisone but did not have an adequate response. Around 1999 she had worsening diarrhea and drainage from her perianal fistula. She was treated with three infusions of infliximab and then it was discontinued for unclear reasons. She denied any reactions to the drug. She was subsequently treated with mercaptopurine for a few years but her disease remained mildly active with diarrhea and episodic drainage from her fistula. She discontinued mercaptopurine around 2012. In 2014, she presented for a second opinion regarding her persistent diarrhea and constant drainage from her perianal fistulas. A repeat magnetic resonance of the pelvis showed complex perianal fistulas with multiple openings but no abscess or fluid collection. She was commenced on antibiotics with ciprofloxacin and metronidazole. We had a long discussion about benefits of infliximab for fistulizing Crohn's disease and a decision was made to restart infliximab. To reduce the risk of a possible infusion reaction, we decided to check infliximab drug levels and antibodies 4 days after her initial infusion to allow for return of the results prior to her second infusion. She tolerated her first infusion and her drug levels returned with $>34.0 \mathrm{ug} / \mathrm{mL}$ and no antibodies to infliximab (ATI) $(<3.1 \mathrm{U} / \mathrm{mL})$ (Prometheus Laboratories Inc. Anser IFX, San Diego CA). She presented for her second infusion and 15 minutes into it she developed flushing, difficulty breathing, nausea, vomiting, tachycardia (101 beats/minutes), and hypotension (88/56). She was given hydrocortisone, ondansetron, lorazepam, famotidine, and diphenhydramine but her symptoms persisted and she was transferred to the emergency department. Over the next 6 hours her symptoms slowly dissipated.

\section{Discussion}

While she declined to obtain repeat infliximab levels, her presentation was consistent with an acute infusion reaction. This presentation was surprising, as it has been presumed that infusion reactions are secondary to antibody development. Usually, infusion reactions occur with the second or third infusion given the exposure to the drug following the first infusion. ${ }^{5,6}$ It is postulated that the antibodies may develop secondary to low drug levels which allows for the development of antibodies against infliximab. ${ }^{6,7}$ Baert and colleagues reported that the presence of infliximab level 2
Correspondence: Joseph D. Feuerstein, Department of Medicine and Division of Gastroenterology, Beth Israel Deaconess Medical Center, Harvard Medical School, 110 Francis Street, Gastroenterology 8E, Boston MA 02215, USA.

E-mail: Jfeuerst@bidmc.harvard.edu

Key words: Inflammatory bowel disease Biologics; Infliximab.

Conflict of interest: the author declares no potential conflict of interest.

Received for publication: 24 July 2015.

Accepted for publication: 5 January 2016.

This work is licensed under a Creative Commons Attribution NonCommercial 4.0 License (CC BYNC 4.0).

(C)Copyright J.D. Feuerstein, 2016

Licensee PAGEPress, Italy

Gastroenterology Insights 2016; 7:6121

doi:10.4081/gi.2016.6121

$\mathrm{ug} / \mathrm{mL}$ without ATI were predictive of response on retreatment, and premedication with hydrocortisone was of unclear benefit. ${ }^{8}$ In our patient, however, testing for ATI prior to her second infusion failed to prevent her acute infusion reaction. It is possible that with the extremely high level of infliximab following the initial infusion, this may mask underlying low-level antibodies.

\section{Conclusions}

Further studies are needed to establish a safer standardized way of reintroducing infliximab and minimize the risk of infusion reactions.

\section{References}

1. Steenholdt C, Brynskov J, Thomsen 00, et al. Individualised therapy is more costeffective than dose intensification in patients with Crohn's disease who lose response to anti-tnf treatment: a randomised, controlled trial. Gut 2014;63:91927.

2. Vaughn BP, Martinez-Vazquez M, Patwardhan VR, et al. Proactive therapeutic concentration monitoring of infliximab may improve outcomes for patients with inflammatory bowel disease: results from a pilot observational study. Inflamm Bowel Dis 2014;20:1996-2003. 
3. Brandse JF, Peters CP, Gecse KB, et al. Effects of infliximab retreatment after consecutive discontinuation of infliximab and adalimumab in refractory Crohn's disease. Inflamm Bowel Dis 2014;20:251-8.

4. Gagniere C, Beaugerie L, Pariente B, et al. Benefit of infliximab reintroduction after successive failure of infliximab and adalimumab in Crohn's disease. J Crohns Colitis 2015;9:349-55.
5. Feuerstein JD, Cheifetz AS. Miscellaneous Adverse Events with Biologic Agents (Excludes Infection and Malignancy). Gastroenterology Clinics of North America. 2014;43(3):543-563.

6. Feuerstein JD, Cullen G, Cheifetz AS. Immune-mediated reactions to anti-tumor necrosis factors in inflammatory bowel disease. Inflamm Bowel Dis 2015;21:117686.
7. Cheifetz A, Smedley M, Martin S, et al. The incidence and management of infusion reactions to infliximab: a large center experience. Am J Gastroenterol 2003;98: 1315-24.

8. Baert F, Drobne D, Gils A, et al. Early trough levels and antibodies to infliximab predict safety and success of reinitiation of infliximab therapy. Clin Gastroenterol Hepatol 2014;12:1474-81. 